Article available at nttp://www.parasite-Journal.org or nttp://dx.dol.org/10.1051/parasite/1995021081

\title{
A HIGH-YIELD OUTBRED SUCKLING MOUSE MODEL OF CRYPTOSPORIDIOSIS
}

\author{
BURAUD M.*, KAPEL N.*,**, BENHAMOU Y.***, SAVEL J.* \& GOBERT J.G.*,**
}

\begin{abstract}
Summary :
Outbred suckling mice (NMRI strain) were used as hosts. They were initially inoculated with oocysts of human origin, and subsequently with parasites recovered from the mouse ileal mucosa Cryptosporidia were counted in an aliquot of whole-ileum homogenate. Parasite load was expressed as cryptosporidia per centimeter of ileum. Serial passage of C. parvum in NMRI mouse litters led to a gradual amplification of parasite burden relative to animals initially inoculated with the human isolate.
\end{abstract}

KEY WORDS : Cryptosporidium. suckling mice. high-yield model.

MOTS CLES : Cryptosporidium. souriceau non sevré. modèle à haut rendement.

everal experimental models of infestation by Cryptosporidium parvum have been developed in newborn animals (Current and Reese, 1986; Novak and Sterling, 1991; Reese et al., 1982; Scaglia et al., 1991; Sherwood et al., 1982).

Adult immunocompetent mice are almost completely resistant to C. parvum parasitization (Sherwood et al., 1982), with the exception of the estrus mouse (Liebler et al., 1986), the naturally infected guinea-pig (Chrisp et al., 1990) and the aged hamster, the latter infection probably being due to age-related immunodeficiency (Rasmussen and Healey, 1992). Experimentally infected immunosuppressed rodents (Brasseur et al., 1988; Rossi et al., 1990; Rehg, 1991; Ungar et al., 1991) and congenitally immunodeficient strains of mice, i.e. $\mathrm{nu} / \mathrm{nu}$ (T cell-deficient) and SCID (which lack both T and $\mathrm{B}$ cells) develop chronic infections which are initially mild but eventually lead to morbidity and death (Ungar et al., 1990; Mead et al., 1991).

Cryptosporidiosis has also been obtained in both consanguineous (Liebler et al., 1986; Novak and Sterling, 1991; Scaglia et al., 1991; Sherwood et al., 1982; Ungar et al., 1990) and outbred mouse strains

\footnotetext{
* Service de Biologie Animale et Parasitaire, UFR des Sciences Pharmaceutiques et Biologiques, Université René Descartes, Paris.

** Service de Parasitologie-Coprologie, Hopital Bichat C.Bernard, Paris, France.

*** Service d'Hépatogastroentérologie, Hopital Pitié-Salpêtrière, FParis.

Phone (33) 1432912 08, poste 121 - Fax (33) 143374360
}

Résumé : DÉveLOPPEMENT D'UN MODELE D'INFECTION MASSIVE À CRYPTOSPORIDIUM CHEZ LE SOURICEAU NON CONSANGUIN, NON SEVRÉ Des souriceaux non sevrés, non consanguins (souche NMRI) sont utilisés comme hôtes. L'infestation initiale est réalisée à partir d'oocystes d'origine humaine alors que les réinfestations sont effectuées avec des parasites récupérés dans la muqueuse iléale des souriceaux. La quantification des cryptosporidies est pratiquée sur un aliquot d'homogénéisat de la totalité de l'iléon. La charge parasitaire est exprimée par détermination du nombre de cryptosporidies par cm d'iléon. Les passages successifs de C. parvum chez des portées de souriceaux NMRI aboutissent à une amplification progressive de la charge parasitaire par rapport à celle obtenue après infestation initiale des souriceaux avec des oocystes d'origine humaine.

(Current and Reese, 1986; Sherwood et al., 1982; Ungar et al., 1990).

With the exception of guinea pigs spontaneously infected by Cryptosporidium parvum, the model used by Chrisp et al. (1990), experimentally infected rodents do not develop physical signs of infection. However, these animal models are useful for studying the replicative cycle, parasite ultrastructure (Current and Reese, 1986; Scaglia et al., 1991), and various aspects of infection (Novak and Sterling, 1991; Sherwood et al., 1982). The efficacy of disinfectants (Korich et al., 1990), drugs (Rehg, 1991) and immunological treatments (Arrowood et al.,1989), as well as the prophylactic effects of certain drugs (Fayer and Ellis, 1993) have been studied in animal models of Cryptosporidium infection.

Infection is proven by the presence of oocysts in the feces or by the detection of various stages of the parasite in sections of the ileum; parasites can also be counted in intestinal mucosal scrapings (Current and Reese, 1986; Scaglia et al., 1991). Quantification of the parasite load is essential for testing anticryptosporidial activity and for studying the natural history of the infection. However, oocyst shedding is related to fecal output and does not take into account intracellular development of the parasite, while histological studies depend on the distribution of the parasite along the intestinal tract. 


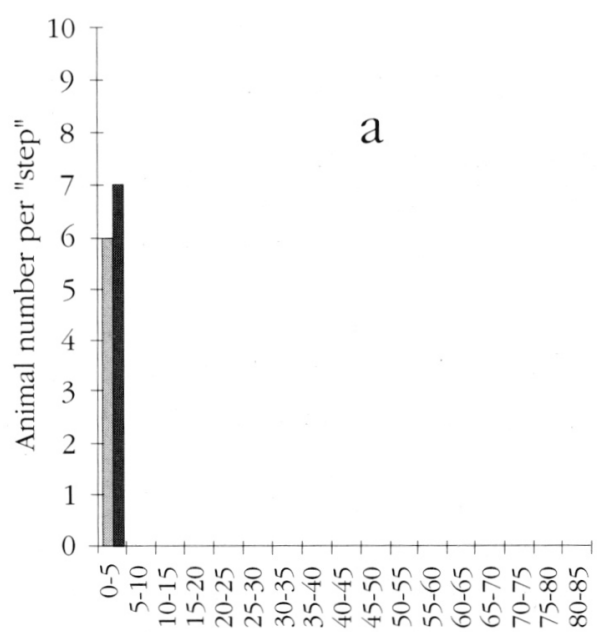

Cryptosporidia per $\mathrm{cm}$ of ileum $\left(\times 10^{3}\right)$

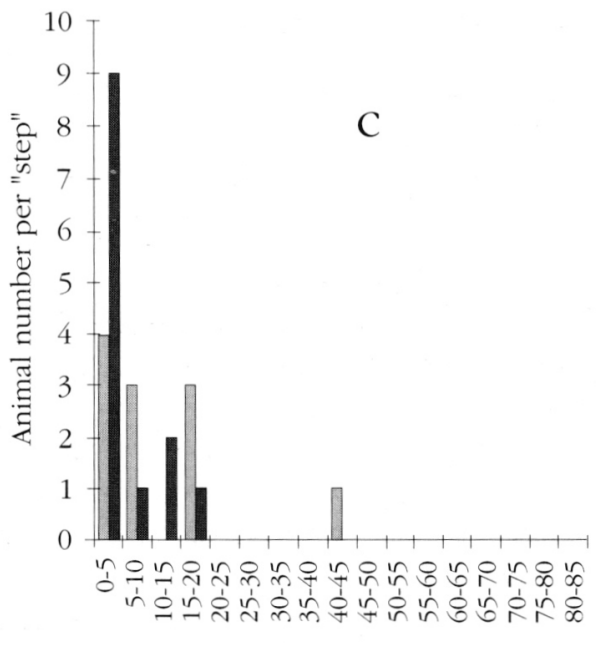

Cryptosporidia per $\mathrm{cm}$ of ileum $\left(\times 10^{3}\right)$

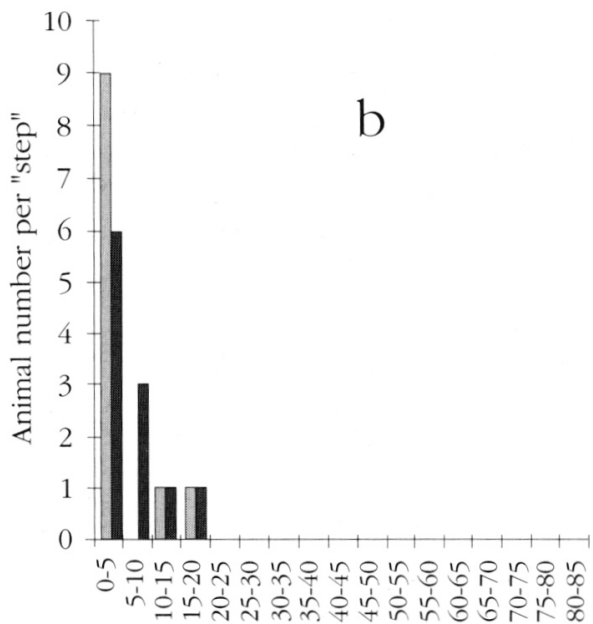

Cryptosporidia per $\mathrm{cm}$ of ileum $\left(\times 10^{3}\right)$

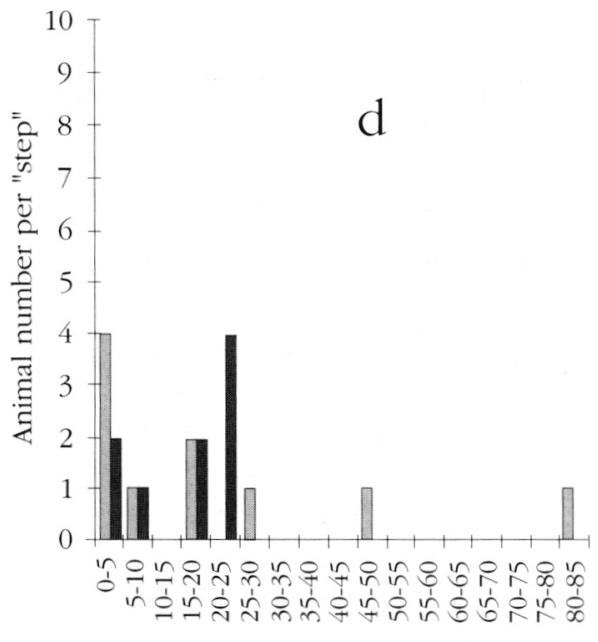

Cryptosporidia per $\mathrm{cm}$ of ileum $\left(\times 10^{3}\right)$

Fig. 1. - Ileal parasite load (steps of $5000 / \mathrm{cm}$ of ileum) in a selected batch of suckling mice inoculated with a homogenate of infected suckling mouse ileum or human oocysts. The stippled bars represent one experiment.

litter a1 ( $n=6)$ : oocysts from human feces

litter b1 $(n=11)$ : cryptosporidia from murine ileal mucosa after 1 passage

litter $c 1(n=11)$ : cryptosporidia originating from murine ileal mucosa after 2 passages

litter d1 ( $\mathrm{n}=10)$ : cryptosporidia originating from murine ileal mucosa after 3 passages

The hatched bars represent another experiment.

litter a2 $(n=7)$ : oocysts from human feces

litter b2 ( $n=11)$ : cryptosporidia from murine ileal mucosa after 1 passage litter c2 $(n=13)$ : cryptosporidia from murine ileal mucosa after 2 passages litter $\mathrm{d} 2(\mathrm{n}=9)$ : cryptosporidia from murine ileal mucosa after 3 passages

\section{MATERIAL AND METHODS}

he aim of this work was to develop an early, high-yield model of cryptosporidiosis in outbred mice by serial reinoculation of suckling animals, with a view to drug screening and studies of the immunological response to C.parvum.

It is based on 4-day suckling NMRI mice. The mice were initially inoculated with oocysts of C. parum isolated from fresh human feces. Debris were eliminated by serial passage through stainless-steel screens with a final mesh size of $32 \mu \mathrm{m}$. The oocysts were then concentrated and purified on a sucrose density gradient (1.04 to 1.10), and collected from the interface (Buraud et al., 1991). After washing in PBS, they were stored in $2.5 \%$ potassium dichromate at $4^{\circ} \mathrm{C}$ for between 8 to 20 days until use. Prior to inoculation, oocysts were washed three times in 0.025 M PBS (pH 7.2) to remove potassium dichromate. They were then resuspended in $1.0 \mathrm{ml}$ of PBS and counted using an haemocytometer. Suckling mice were inoculated by gavage (d0) with $100 \mu \mathrm{l}$ of concentrated material containing $10^{6}$ oocysts. Infection was checked on 
day 6 post-inoculation. Parasite load was determined by counting cryptosporidia in an ileal homogenate. As the terminal ileum is the intestinal section most heavily infected with cryptosporidia in consanguineous BALB/c mice (Novak and Sterling, 1991), we focused on this region to evaluate the severity of infection. Mice were killed by chloroform asphyxiation. The small intestine was removed from the abdomen, and the ileum, easily recognizable by its color and smaller diameter than the jejunum, was isolated and measured without traction. The ileum was then split lengthwise and homogenized for 25 seconds in $1 \mathrm{ml}$ of PBS using a glass tissue grinder with a Teflon pestle mounted on a drill press operating at $300 \mathrm{rpm}$ (Potter apparatus). An aliquot $(20 \mu \mathrm{l})$ of the homogenate was smeared onto a glass slide $\left(2 \mathrm{~cm}^{2}\right)$ and stained by using a modified Ziehl-Neelsen technique. Cryptosporidia are easily detected at magnification of $\times 200$ (Henriksen and Pohlenz, 1981). Parasite load was expressed as cryptosporidia per centimeter of ileum, as follows :

$$
\mathrm{N}=\mathrm{n} \times 50 / \mathrm{L}
$$

where $\mathrm{n}$ is the total number of parasites counted in the smear, $L$ the total length of ileum $(\mathrm{cm})$ homogenized in $1 \mathrm{ml}$ of PBS, and 50 the coefficient used to transform the number of cryptosporidia in $20 \mu \mathrm{l}$ into the number present in the entire ileum $(1 \mathrm{ml})$.

Four consecutive litters of 4-day-old NMRI mice were then infected by ingestion of a day- 6 ileal homogenate. The homogenates were kept for 7 to 15 days at $4^{\circ} \mathrm{C}$ after the addition of penicillin $(100 \mathrm{IU} / \mathrm{ml})$, streptomycin $(100 \mu \mathrm{g} / \mathrm{ml})$ and amphotericin $\mathrm{B}(0.25$ $\mu \mathrm{g} / \mathrm{ml})$, until the next inoculation. Subsequent inoculations consisted of $10^{4}$ cryptosporidia (all stages) in $100 \mu \mathrm{l}$ of PBS. All experiments were performed in duplicate [litter a: mice inoculated with human oocysts ( $a 1, n=6 ; a 2, n=7$ ); litter $b$ : mice inoculated with cryptosporidia from ileal homogenate after 1 passage in mice (b1, $\mathrm{n}=11 ; \mathrm{b} 2, \mathrm{n}=11)$; litter $\mathrm{c}$ : mice inoculated with cryptosporidia from ileal homogenate after 2 passages $(\mathrm{c} 1, \mathrm{n}=11 ; \mathrm{c} 2, \mathrm{n}=13)$ and litter $\mathrm{d}$ : mice inoculated with cryptosporidia from ileal homogenate after 3 passages $(\mathrm{d} 1, \mathrm{n}=10$; 2 , $\mathrm{n}=9$ ). Parasite load was checked as previously described. A histogram was constructed for each successive litter, showing the number of animals in the different parasite load categories ( steps of 5000 cryptosporidia per centimeter of ileum).

\section{RESULTS}

ll 10-day mice were positive for C. parum in all experiments. Parasite load varied considerably from within a given litter, from 100 to 4000 after inoculation with oocysts isolated from human feces (litters a1 and a2, fig. 1) and from 300 to 82000 after inoculation with cryptosporidia originating from murine intestinal mucosa (litters b to d, fig. 1). Parasite load increased regularly from litter b (2nd passage in mice) to litter $d$ (4th passage) and was significantly increased after passage 4 (ANOVA; $\mathrm{p}<0.05)$.

Expressed as the cumulative mean per litter, the results were as follows : litter a1 $(n=6), 5000$; litter a2 $(n=7), 5000$; litter b1 $(n=11), 7272$; litter b2 $(n=11), 8636$; litter $\mathrm{c} 1(\mathrm{n}=11), 14090$; litter $\mathrm{c} 2$ $(n=13), 8076$; litter d1 $(n=10), 23500$; litter $d 2(n=9)$, 17777 cryptosporidia per $\mathrm{cm}$ of ileum.

Few parasites were found when the homogenates were used 48 hours after collection, whereas all the animals were successfully inoculated with homogenate stored in PBS at $+4^{\circ} \mathrm{C}$ for 5 to 7 days, with a maximum of 60 days.

\section{DISCUSSION}

arasite load can be determined by counting the number of parasites present on longitudinal villi in two randomly selected high-power fields (X 400) (Novak and Sterling, 1991). However, when few parasites are present, they are usually concentrated in one area. Fayer et al. (1993) examined five areas within histologic sections of ileum, caecum and colon and assigned a score for the percentage of epithelium parasitized. We considered that counting an aliquot of the entire homogenized ileum, which contains both free and intracellular forms of the parasite, is more representative of the degree of infection than the use of stained $5-\mu \mathrm{m}$ slices of ileum. We obtained a mean value for parasite load in the whole ileum, rather than point values dependent on the section examined, particularly when few parasites are present. Furthermore, this counting method is not influenced by intestinal transit speed or irregular fecal excretion.

We used outbred mice to obtain larger litters; outbred and inbred mice have similar susceptibility to C. parvum infection (Sherwood et al., 1982).

The use of suckling mouse ileum homogenates for inoculation rather than oocysts isolated from human feces means that the inoculum can be 100 times smaller and yet provide 20 times as many cryptosporidia. Indeed, the ileal homogenate from a heavily infected mouse contains several hundred thousand crytosporidia. The regular increase in parasite load observed between passage 2 (from a to b) and passage 4 (from $c$ to d) points to increased infectivity. The gradual increase in parasite load is not only due to amplifica- 
tion of the normal life cycle by repeated penetration into enterocytes, but also to an increase in virulence through serial passage in the host (a common phenomenon in the experimental setting).

A further advantage of this model is that oocyst purification from mouse ileal homogenate is far easier than from human or calf feces. This high-yield model should prove useful for studying the natural history of C. paroum infection, drug screening and studies of immunological approaches aimed at eliminating the infection.

\section{REFERENCES}

Arrowood M.J., Mead J.R., Mahrt J.L. \& Sterling C.R. Effects of immune colostrum and orally administered antisporozoite monoclonal antibodies on the outcome of Cryptosporidium parvum infection in neonatal mice. Infection and Immunity, 1989, 57, 2283-2288.

Brasseur P., Leméteil D. \& Ballet J.J. Rat model for human cryptosporidiosis. Journal of Clinical Microbiology, 1988, 26, 1037-1039.

Buraud M., Forget E., Favennec L., Bizet J., Gobert J.G. \& Deluol A.M. Sexual stage development of cryptosporidia in the Caco-2 cell line. Infection and Immunity, 1991, 59, 4610-4613.

Chrisp C.E., Reid W.C., Rush H.G., Suckow M.A., Bush A. \& Thomann M.J. Cryptosporidiosis in guinea pigs: an animal model. Infection and Immunity, 1990, 58, 674-679.

Current W.L. \& ReEse N.C. A comparison of endogenous development of three isolates of Cryptosporidium in suckling mice. The Journal of Protozoology, 1986, 33, 98108.

FAYER R. \& Ellis W. Glycoside antibiotics alone and combined with tetracyclines for prophylaxis of experimental cryptosporidiosis in neonatal $\mathrm{BALB} / \mathrm{c}$ mice. The Journal of Parasitology, 1993, 79, 553-558.

Henriksen S. \& Pohlentz J. Staining of cryptosporidia by a modified Ziehl-Neelsen technique. Acta Veterinaria Scandinavica, 1981, 22, 594-596.

Korich D.G., Mead J.R., Madore M.S., Sinclair N.A. \& STERLING C.P. Effects of ozone, chlorine dioxide, chlorine and monochloramine on Cryptosporidium parvum oocyst viability. Applied and Environmental Microbiology, 1990, 56, 1423-1428.

Liebler E.M., Pohlenz J.F. \& Woodmansee D.B. Experimental intrauterine infection of adult BALB/c mice with Cryptosporidium sp. Infection and Immunity, 1986, 54, 255-259.

Mead J.R., Arrowood M.J., Sidwell R.S. \& Healey M.C. Chronic Cryptosporidium parvum infections in congenitally immunodeficient SCID and nude mice. The Journal of infectious diseases, 1991, 163, 1297-1304

NovaK S.M. \& STERLing C.R. Susceptibility dynamics in neonatal BALB/c mice infected with Cryptosporidium parvum. The Journal of Protozoology, 1991, 38, 102S-104S.

Rasmussen \& Healey. Cryptosporidium parvum : Experimental infections in aged syrian golden hamsters. The
Journal of infectious diseases, 1992, 165, 769-772.

Reese N.C., Current W.L., Ernst J.V. \& Bailey W.S Cryptosporidiosis of man and calf : a case report and results of experimental infections in mice and rats. The American Journal of Tropical Medicine and Hygiene, 1982, 31, 226-229.

REHG J.E. Anticryptosporidial activity is associated with specific sulfonamide in immunosuppressed rats. The Journal of Parasitology, 1991, 77, 238-240.

Rossi P., Pozio E., Besse M.G., Gomez Morales M.A. \& LA RosA G. Experimental cryptosporidiosis in hamsters. Journal of Clinical Microbiology, 1990, 28, 356-357.

Scaglia M., Bruno A., Chichino G., Atzori C., Cevini C. \& GATTI S. Cryptosporidium parvum life cycle in suckling mice : a Nomarski interference-contrast study of a human derived strain. The Journal of Protozoology, 1991, 38, 118S-121S.

Sherwood D., Angus K.W., Snodgrass D.R. \& Tzipori S. Experimental cryptosporidiosis in laboratory mice. Infection and Immunity, 1982, 38, 471-475.

Ungar B.L.P., Burris J.A., Quinn C.A. \& Finkelman F.D. New mouse models for chronic Cryptosporidium infection in immunodeficient hosts. Infection and Immunity, 1990, 58, 961-969.

Ungar B. L.P., KaO T.C., Burris J.A. \& Finkelman F.D. Cryptosporidium infection in an adult mouse model. Independent roles for IFN-g and CD4+ T lymphocytes in protective immunity. Journal of immunology, 1991, 147 , 1014-1022. 